\title{
Redução de cromo hexavalente por bactérias isoladas de solos contaminados com cromo
}

\author{
Reduction of hexavlent chromium by isolated bacteria of contaminated soils with chromium
}

\author{
Daniele Conceição ${ }^{I}$ Rodrigo Jacques ${ }^{\text {III }}$ Fatima Bento ${ }^{\text {II }}$ Amauri Simonetti ${ }^{\text {II }}$ \\ Pedro Selbach ${ }^{\text {III }}$ Flavio Camargo ${ }^{\text {III }}$
}

\section{RESUMO}

A redução do $C r(V I)$ para $C r(I I I)$ diminui a toxidade deste metal no ambiente, uma vez que o Cr(III) é insolúvel às membranas biológicas. Assim, a redução microbiana do Cr(VI) é uma alternativa para reduzir os impactos ambientais causados por este metal, utilizado em diversos processos industriais. O objetivo deste trabalho foi selecionar microrganismos a partir de solo contaminado com cromo e caracterizar sua capacidade de redução do $\mathrm{Cr}(\mathrm{VI})$ durante o crescimento celular. A atividade de redução do Cr(VI) pelos isolados foi quantificada com o reagente de sdifenilcarbazida. No isolamento, foram obtidas 20 bactérias resistentes a cromo(VI); seis destas foram capazes de reduzir acima de $100 \mathrm{mg} \mathrm{L}^{-1} \mathrm{Cr}(\mathrm{VI})$ em 24 horas. As bactérias selecionadas foram eficientes na redução do $\mathrm{Cr}(\mathrm{VI})$ e apresentam potencial para outros estudos, visando à aplicação em processos de biorremediação.

Palavras-chave: biorremediação, cromo hexavalente, bactérias resistentes a cromo.

\section{ABSTRACT}

The reduction of $\mathrm{Cr}(\mathrm{VI})$ to $\mathrm{Cr}(\mathrm{III})$ decrease the toxic effect of this metal in the environment, because $\mathrm{Cr}(\mathrm{III})$ is insoluble to the biological membranes. The microbial reduction of $\mathrm{Cr}(\mathrm{VI})$ it is an alternative to reduce the environmental impacts caused by this metal used in several industrial processes. The objective of this research was to select microorganisms from chromium contaminated soil and to characterize their ability to reduce $\mathrm{Cr}(\mathrm{VI})$. The activity of reduction of $\mathrm{Cr}(\mathrm{VI})$ for the isolated was quantified with s-diphenylcarbazide. A group of 20 chromium resistant bacteria were isolated; six of these were able to reduce $100 \mathrm{mg} \mathrm{L}^{-1} \mathrm{Cr}(\mathrm{VI})$ in 24 hours. The isolated bacteria, from contaminated soil can remediate chromate and presented potential for other studies seeking their application in bioremediation processes.
Key words: bioremediation, hexavalente chromium, chromium-resistant bacteria.

\section{INTRODUÇÃo}

O estágio atual de desenvolvimento da sociedade tem contribuído grandemente para a geração de resíduos agrícolas e industriais com grande potencial de contaminação de ambientes, como o solo e a água (TEDESCO et al., 1995). É necessário o desenvolvimento de tecnologias para a remediação destes ambientes, em que a biorremediação, utilizando microrganismos nativos ou modificados geneticamente, pode ser uma alternativa eficiente e ao mesmo tempo de baixo custo.

No Rio Grande do Sul, destaca-se a poluição causada pelos resíduos da indústria coureirocalçadista. No curtimento de peles ocorre a geração de lodos nas Estações de Tratamento de Esgotos (ETEs) com elevado potencial poluidor, principalmente de cromo, que é o mais utilizado no processamento. O cromo na forma hexavalente é um potente agente mutagênico e pode causar carcinomas, entre outras patologias (CHIRWA\& WANG, 2000). Para a eliminação do cromo na forma oxidada, tem sido proposta a redução do $\mathrm{Cr}(\mathrm{VI})$ a $\mathrm{Cr}(\mathrm{III})$, pois o cromo na forma trivalente é mais estável e de baixa toxicidade (CODD et al., 2001). A redução do cromo nos sistemas de tratamento convencionais tem sido realizada através de processos

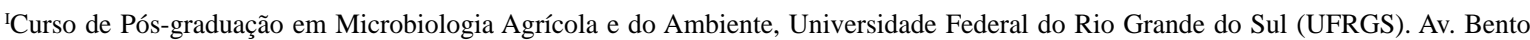
Gonçalves, 7712, 91540-000, Porto Alegre, RS, Brasil. E-mail: daniele.conceicao@gmail.com.

"Departamento de Microbiologia, Instituto de Ciências Básicas da Saúde, UFRGS, Porto Alegre, RS, Brasil.

IIIDepartamento de Solos, Faculdade de Agronomia, UFRGS, Porto Alegre, RS, Brasil.
} 
químicos e físico-químicos de elevado custo de implantação e de baixa eficiência no ambiente. Atualmente, para a remediação de ambientes contaminados com Cr(VI), tem sido proposta a utilização de microrganismos (CERVANTES et al., 2001). Destacase entre os produtos a adição de enzimas redutoras de cromato, produzidas a partir de microrganismos nativos do solo ou melhorados geneticamente (DICK \& TABATABAI, 1992). Alguns mecanismos de resistência têm sido propostos para microrganismos, como a sorção, o acúmulo, a precipitação, o efluxo e a redução de $\mathrm{Cr}(\mathrm{VI})$ a $\mathrm{Cr}(\mathrm{III})$ através de enzimas que transferem elétrons e reduzem o metal. Entre estes mecanismos, a redução parece ter grande potencial biotecnológico para a biorremediação (KEYHAN et al.,2003).

O presente trabalho tem como objetivo selecionar microrganismos resistentes ao cromo hexavalente, a partir de um solo agrícola com histórico de contaminação por este metal, e caracterizá-los quanto a sua capacidade de biorremediação do cromo(VI).

\section{MATERIAL E MÉTODOS}

As amostras de solo foram retiradas em 12 pontos (na profundidade de 0 a $30 \mathrm{~cm}$ ) de uma área agrícola do município de Roca Sales-RS contaminada com cromo proveniente de descarte de lodo de curtume. As amostras foram analisadas quanto à concentração do cromo total, conforme metodologia descrita por TEDESCO et al. (1995). Para o isolamento, foram selecionadas amostras de solo com concentrações baixas, 344 e 355 $\mathrm{mg} \mathrm{L}^{-1}$ (amostras 1 e 2), e altas, 466, 510 e 835 $\mathrm{mg} \mathrm{L}^{-1}$ (amostras 3, 4 e 5) de cromo total.

Para a seleção de microrganismos resistentes, amostras de um grama de solo foram adicionadas a $200 \mathrm{ml}$ de caldo nutritivo com 500 $\mathrm{mg} \mathrm{L}^{-1}$ de $\mathrm{K}_{2} \mathrm{Cr}_{2} \mathrm{O}_{7}$ e incubadas por 24 horas, a 150rpm e a $30^{\circ} \mathrm{C}$. Após este período, $200 \mu \mathrm{L}$ foram transferidos para outro erlenmeyer com o mesmo meio e incubado nas mesmas condições (sendo este processo repetido três vezes), sendo então retirados $100 \mu \mathrm{L}$ para o plaqueamento em ágar nutritivo contendo $500 \mathrm{mg} \mathrm{L}^{-1}$ de Cr(VI), realizando-se então o isolamento de colônias puras.

Os isolados obtidos foram avaliados quanto à capacidade de crescimento em caldo nutritivo contendo $\mathrm{K}_{2} \mathrm{Cr}_{2} \mathrm{O}_{7}$. As colônias puras foram inoculadas em frascos de erlenmeyer contendo $30 \mathrm{ml}$ de caldo nutritivo com 250 e $500 \mathrm{mg} \mathrm{L}^{-1}$ de $\mathrm{Cr}(\mathrm{VI})$ e incubadas por 24 horas, a $150 \mathrm{rpm}$ e $30^{\circ} \mathrm{C}$, sendo o inóculo padronizado a uma absorbância de 0,3, em espectrofotômetro a 600nm. Após incubação por 24 horas, a $150 \mathrm{rpm} \mathrm{e} 30^{\circ} \mathrm{C}$, foram determinadas a densidade óptica (DO) em espectrofotômetro a 600nm e a concentração final do $\mathrm{Cr}(\mathrm{VI})$ no caldo nutritivo, com o reagente de s-difenilcarbazida em espectrofotômetro a 540nm(GRANER, 1972).

Para avaliar o efeito do $\mathrm{pH}$ e da temperatura na redução do cromo e para a caracterização da atividade ótima para cada isolado, estes foram crescidos separadamente, padronizados como descrito e inoculados em caldo nutritivo contendo $50 \mathrm{mg} \mathrm{L}^{-1}$ de $\mathrm{Cr}(\mathrm{VI})$. O pH do meio foi ajustado para 5,0; 6,0; 7,0; 8,0; 9,0 e 10,0 e temperaturas de 25, 30, 35 e $40^{\circ} \mathrm{C}$. As determinações de DO e a concentração do $\mathrm{Cr}(\mathrm{VI})$ foram realizadas após 12 horas de incubação, a 150rpme $30^{\circ} \mathrm{C}$.

A atividade enzimática de redução do $\mathrm{Cr}(\mathrm{VI})$ foi determinada com o extrato celular dos isolados, através de sonicação das células em banho de gelo com três pulsos de 20 segundos, a 35W e centrifugadas a $10.000 \mathrm{rpm}$, por 45 minutos, para a retirada de restos celulares. Em seguida, as células foram ressuspendidas em $10 \mathrm{~mL}$ de tampão fosfato $(50 \mathrm{mM}, \mathrm{pH} 7,0)$, sendo quantificada a concentração de proteína no sobrenadante, conforme descrito por BRADFORD (1976).

Para avaliar o efeito de diferentes íons na atividade da enzima redutora de cromo, preparou-se a reação de $\mathrm{NADH}(0,2 \mathrm{mM})$, tampão fosfato $(50 \mathrm{mM}, \mathrm{pH}$ $7,0)$ com $\mathrm{Cr}(\mathrm{VI})\left(1 \mathrm{mg} \mathrm{L}^{-1}\right)$ e o íon a ser testado. O volume final da reação foi de $1,5 \mathrm{ml}$, sendo incubado a $30^{\circ} \mathrm{C}$ por 15 minutos. Após este período, a solução de sdifenilcarbazida era adicionada, procedendo-se à análise em espectrofotômetro 540nm. O teste foi realizado com a mesma concentração de proteína presente no extrato celular, para todos os isolados. Neste teste, os isolados foram comparados com o Bacillus sp. ES29, uma bactéria comprovadamente redutora de Cr(VI), isolada por CAMARGO et al. (2003). Como inibidores, foram testados íons, adicionados à mistura de reação na forma de sulfato de cobre, cloreto de magnésio, cloreto de mercúrio, cloreto de manganês e sulfato de sódio, todos na concentração de $1 \mathrm{mM}$.

Para a identificação de gênero dos isolados que mais eficientemente reduziram o $\mathrm{Cr}(\mathrm{VI})$ foram realizados os testes segundo MACFADDIN (1980).

\section{RESULTADOS E DISCUSSÃO}

Das cinco amostras de solo, foram isoladas 20 colônias de bactérias morfologicamente distintas. A técnica de enriquecimento mostrou-se eficiente para o isolamento de microrganismos resistentes a cromo, em 
solos com histórico de contaminação. No presente trabalho, foi obtido um número significativo de bactérias resistentes a partir das amostras, tendo em vista que apenas $10 \%$ das bactérias presentes no solo são culturáveis (AMANN et al., 1994). Nas amostras com maior concentração de cromo total (CT), verificouse um número maior de isolados, indicando que a presença de altas concentrações de cromo pode ter exercido pressão para selecionar os organismos resistentes a este metal que foi adicionado ao solo.

Para selecionar as bactérias mais eficientes na redução do $\mathrm{Cr}(\mathrm{VI})$, os 20 isolados foram crescidos em caldo LB com $250 \mathrm{mg} \mathrm{L}^{-1}$ de $\mathrm{K}_{2} \mathrm{Cr}_{2} \mathrm{O}_{7}$ (Tabela 1). Entre os isolados, apenas três apresentaram redução do cromo abaixo de $10 \%$ do inicial, onze isolados apresentaram redução acima de $15 \%$ e seis reduziram acima de $50 \%$ do $\mathrm{Cr}(\mathrm{VI})$, ou seja, reduziram acima de $125 \mathrm{mg} \mathrm{L}^{-1}$ em 24 horas. As maiores percentagens de redução do $\mathrm{Cr}(\mathrm{VI})$ foram as dos isolados que apresentaram DO elevada. As bactérias mais eficientes na redução (capazes de reduzir acima de $50 \%$ do cromo) foram os isolados 6, 11, 12, 16, 18 e 20. Este último isolado foi o mais eficiente na redução, transformando $64 \%$ do $\mathrm{Cr}$ (VI) a Cr(III) e foi obtido da amostra de solo com maior concentração de cromo total.

Entre os mecanismos de resistência a elevadas concentrações de cromo, pode-se citar o acúmulo intracelular, a baixa absorção e a produção de metalotioneína (BLINDAUER et al., 2001). Dessa forma, observa-se que muitos microrganismos são resistentes a baixas concentrações de $\mathrm{Cr}(\mathrm{VI})$, porém há necessidade de avaliar o potencial de redução do metal em maiores concentrações, para a identificação dos microrganismos mais eficientes.

Os seis isolados mais eficientes foram testados para avaliar sua resistência à concentração de $500 \mathrm{mg} \mathrm{L}^{-1}$ de $\mathrm{Cr}(\mathrm{VI})$, assim como o tempo de redução (Figura 1). O crescimento celular não foi inibido pela presença de $500 \mathrm{mg} \mathrm{L}^{-1}$ de $\mathrm{Cr}(\mathrm{VI})$. A maior DO e redução foi novamente obtida com o isolado 20, seguido dos isolados 6 e 12, que também apresentaram grande atividade de redução do cromo nesta concentração. O mecanismo de redução enzimática do $\mathrm{Cr}$ (VI) a Cr(III) tem sido observado em bactérias, sendo associado à presença de enzimas cromato redutases (CAMARGO et al., 2003; DERMOU et al., 2005). Apenas três isolados (6, 12 e 20) foram capazes de crescer em caldo nutritivo contendo $750 \mathrm{mg} \mathrm{L}^{-1}$ de $\mathrm{Cr}(\mathrm{VI})$, sendo então esta concentração limitante para o crescimento dos outros isolados. O isolado 20 foi novamente o que apresentou maior capacidade de redução, porém ela foi de apenas 40\% da concentração inicial (dados não apresentados).

De modo geral, os $\mathrm{pH}$ que favoreceram maior redução foram 7,0 e 8,0, sendo que, os isolados cresceram e reduziram o cromo na faixa de $\mathrm{pH}$ de 5,0 a 9,0, (Figura 2), demonstrando capacidade de adaptação, às variações ambientais. Para esta adaptação o microrganismo deve ser capaz de manter o pH

Tabela 1 - Redução do cromo pelas bactérias isoladas após 24 horas de crescimento em caldo contando $250 \mathrm{mg} \mathrm{L}^{-1}$ de $\mathrm{Cr}_{(\mathrm{VI})}\left(\mathrm{K}_{2} \mathrm{CrO}_{7}\right)$.

\begin{tabular}{|c|c|c|c|c|}
\hline Isolados & Amostra de solo & Concentração restante de $\mathrm{Cr}(\mathrm{VI})\left(\mathrm{mg} \mathrm{L}^{-1}\right)$ & Redução (\%) & Densidade ótica $\left(\mathrm{A}_{600 \mathrm{~nm}}\right)$ \\
\hline 1 & 1 & 195,8 & 22 & 0,980 \\
\hline 2 & 1 & 164,5 & 34 & 0,838 \\
\hline 3 & 1 & 194,4 & 22 & 0,835 \\
\hline 4 & 2 & 229,6 & 8 & 0,540 \\
\hline 5 & 2 & 174,6 & 34 & 0,835 \\
\hline 6 & 3 & 114,6 & 54 & 1,730 \\
\hline 7 & 3 & 240,2 & 4 & 0,440 \\
\hline 8 & 3 & 176,4 & 29 & 0,762 \\
\hline 9 & 3 & 166,7 & 33 & 0,808 \\
\hline 10 & 3 & 210,2 & 16 & 0,619 \\
\hline 11 & 4 & 104,5 & 58 & 1,115 \\
\hline 12 & 4 & 96,1 & 62 & 1,980 \\
\hline 13 & 5 & 210,8 & 16 & 0,427 \\
\hline 14 & 5 & 194,7 & 22 & 0,819 \\
\hline 15 & 5 & 198,2 & 21 & 0,721 \\
\hline 16 & 5 & 100,9 & 60 & 1,440 \\
\hline 17 & 5 & 188,5 & 25 & 0,460 \\
\hline 18 & 5 & 102,4 & 59 & 1,350 \\
\hline 19 & 5 & 238,4 & 5 & 0,422 \\
\hline 20 & 5 & 90,9 & 64 & 1,840 \\
\hline Sem inóculo & - & 249,6 & - & - \\
\hline
\end{tabular}




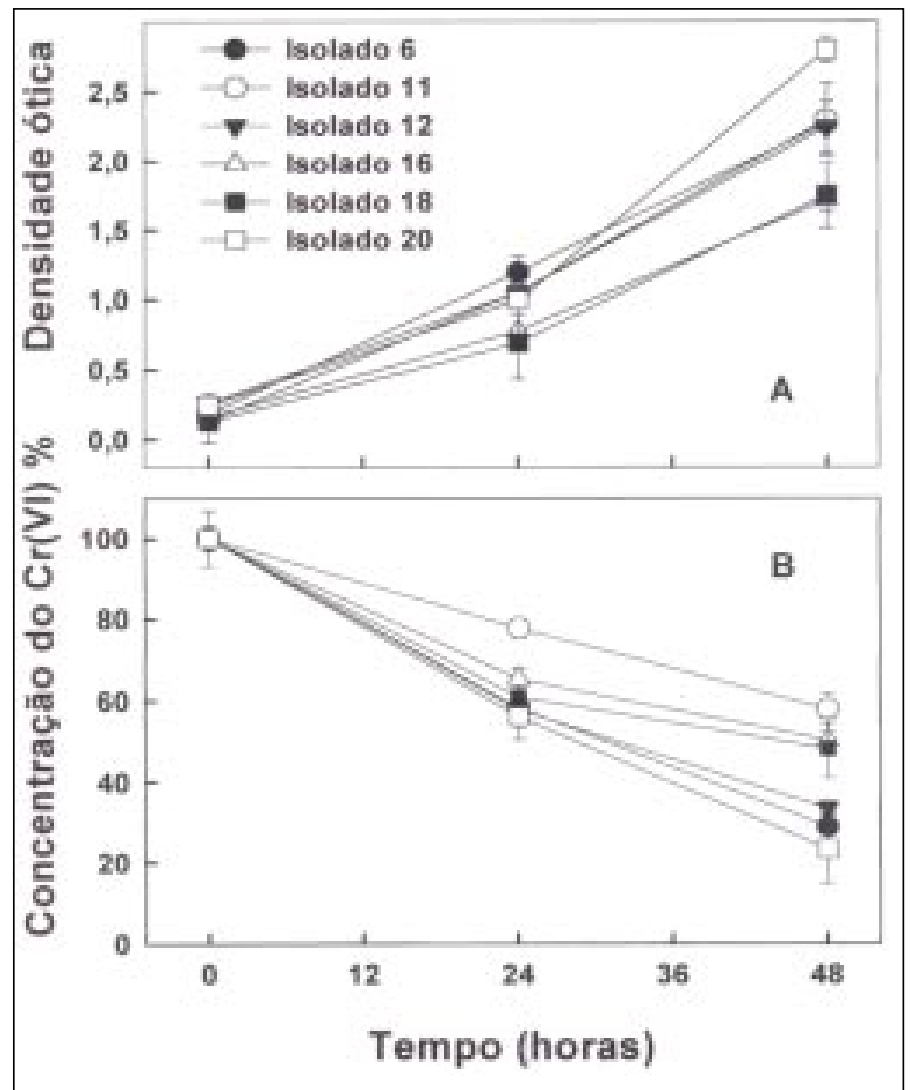

Figura 1 - Crescimento (A) e redução do $\operatorname{Cr}(\mathrm{VI})$ (B) pelos isolados em caldo nutritivo com 500mg L ${ }^{-1}$ de $\mathrm{Cr}(\mathrm{VI})$ (dados são médias de duas repetições e as barras representam o erro padrão).

intracelular em torno de 7,5, não importando o pH do caldo de crescimento. Isto ocorre pela extrusão ou absorção de prótons pela célula microbiana. Foi observado, neste trabalho e no de CAMARGO et al. (2003), que, para a maioria dos isolados, o pH ótimo de crescimento está relacionado com o pH de maior redução do cromo. Isto talvez possa ser associado com o número de células responsáveis pela redução, ou que somente após a redução do Cr(VI) no pH ideal há diminuição da concentração deste metal, favorecendo o crescimento dos microrganismos. Outro fator a ser considerado é que se a redução é mediada por enzimas, podem ser altamente vulneráveis a fatores ambientais, sendo sua atividade inibida ou até destruída por calor excessivo ou variações no $\mathrm{pH}$, sendo esta sensibilidade variável para cada enzima.

A capacidade de redução de $100 \%$ do $\mathrm{Cr}(\mathrm{VI})$ presente no caldo nutritivo pelo isolado 20 foi observada no pH de 5,0 a 9,0, sendo inibida sua atividade de redução apenas em pH 10,0 (Figura 2). A atividade ótima de redução do $\mathrm{Cr}(\mathrm{VI})$ deste isolado ocorreu em pH 7,0, 8,0 e 9,0 e nas temperaturas de 25 a $35^{\circ} \mathrm{C}$ (Figura 3), demonstrando grande adaptação a esses dois fatores ambientais, o que o torna promissor para futuros estudos de biorremediação.

Para avaliar o efeito da temperatura no crescimento e na redução do $\mathrm{Cr}(\mathrm{VI})$, foram testadas variações de 25 , 30, 35 e $40^{\circ} \mathrm{C}$ (Figura 3). Na temperatura de $35^{\circ} \mathrm{C}$, houve inibição do crescimento de três isolados e esta inibição se estendeu para todos os isolados a $40^{\circ} \mathrm{C}$. O isolado 20 apresentou maior DO em todas as temperaturas avaliadas. Em $30^{\circ} \mathrm{C}$, foram obtidas as maiores DO para todos os isolados, porém não as melhores reduções.

Os isolados apresentaram características diferentes quanto à redução do $\mathrm{Cr}(\mathrm{VI})$ na presença de íons. Foi verificada a dependência de NADH, como doador de elétrons para a redução de $\mathrm{Cr}(\mathrm{VI})$ por todos os isolados. Segundo SUZUKI et al. (1992), o NADH atua como doador de elétrons para atividade enzimática, formando o intermediário $\mathrm{Cr}(\mathrm{V})$, que aceita mais dois elétrons de outras duas moléculas da mesma coenzima para formar $\mathrm{Cr}(\mathrm{III})$.

Na figura 4, são apresentados os efeitos causados na atividade enzimática dos isolados pela adição de cátion divalentes. A presença de sulfato de cobre estimulou a atividade de redução da maioria dos isolados, sendo esta $60 \%$ maior que o controle para o isolado 20. Este estímulo foi observado com adição de cloreto de cobre por CAMARGO et al. (2003) e KEYHAN et al. (2003), segundo os quais a atividade de redução do $\mathrm{Cr}(\mathrm{VI})$ pelo microrganismo avaliado foi estimulada pela adição de sulfato e cloreto de cobre. A atividade de redução do $\mathrm{Cr}(\mathrm{VI})$ pelos isolados 6 e 12 praticamente não foi estimulada pela presença de íons cobre. Este fato também foi observado por PARK et al. (2000), para quem a adição de 5 a $25 \mathrm{mM}$ deste íon não afetava atividade de redução do $\mathrm{Cr}(\mathrm{VI})$ pelos seus isolados. As maiores inibições ocorreram pelo mercúrio e magnésio (72\%), seguidas por sódio e molibdênio.

A atividade do isolado 11 não foi estimulada pela presença de nenhum íon testado. Pelo contrário, sua atividade foi inibida pelos íons, sendo praticamente suprimida pelo Mn e Na. Por outro lado, este isolado apresentou baixa inibição da atividade na presença de $\mathrm{Hg}$ e Mg. Estes resultados confirmam a idéia da existência de diferentes tipos de enzimas com capacidade de redução do $\mathrm{Cr}(\mathrm{VI})$.

A atividade enzimática dos isolados 16 e 18 foi similar. Houve estímulo pela presença de cobre e inibição pelo mercúrio, sendo que, para o isolado 16, a 


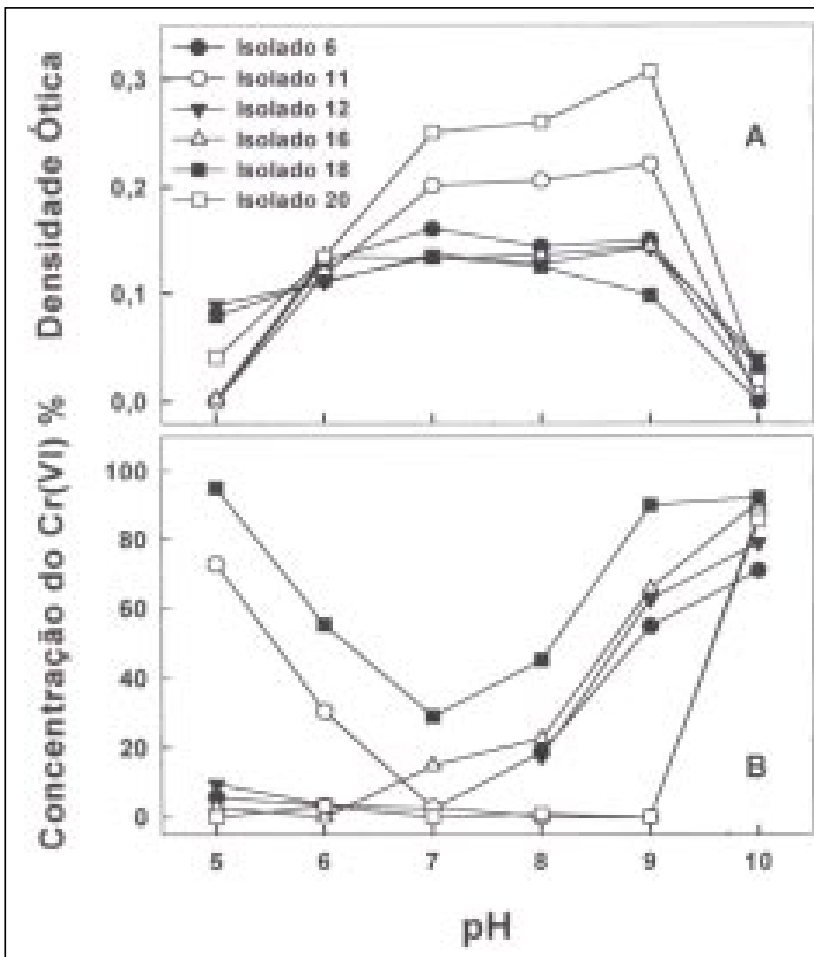

Figura 2 - Influência do pH no crescimento celular (A) e na redução do cromo(VI) (B) presente no caldo nutritivo (50mg $\left.\mathrm{L}^{-1}\right)$ após 12 horas de incubação (dados são médias de duas repetições).
As células procarióticas normalmente não produzem este ácido, sendo a glutationa seu principal redutor não-enzimático (STANDEVEN \& WETTERHAHN, 1992). Porém, esta redução é ínfima se comparada à redução enzimática realizada por organismos resistentes. A enzima redutora de cromo é de grande importância para os organismos que a produzem, pois realiza a rápida redução do $\mathrm{Cr}(\mathrm{VI})$ a $\mathrm{Cr}(\mathrm{III})$, sendo este rapidamente eliminado para o meio externo, antes de interagir com as macromoléculas, como DNA e proteínas, o que poderia acarretar danos à célula.

O isolado 6 foi identificado como pertencente ao gênero Aeromonas. LOUKIDOU et al. (2004) testaram a retirada de $\mathrm{Cr}(\mathrm{VI})$ de um efluente utilizando um sistema de biorreator com Aeromonas caviae através da sorção deste metal às células bacterianas. $\mathrm{O}$ isolado 11 pertence ao gênero Aureobacterium, que também já foi relatado com resistência e atividade de redução do $\mathrm{Cr}(\mathrm{VI})$ por FRANSCISCO et al. (2002), sendo por eles isolada uma Aureobacterium esteroaromaticum de lodo ativado, utilizado para tratamento de esgoto, contendo metais presença deste íon suprimiu a atividade enzimática. Porém, a inibição para o isolado 18 foi menor por $\mathrm{Hg}$ do que a causada pelo Mg. A forte inibição causada pelo $\mathrm{Hg}$ era esperada para todos os isolados por este íon ter forte atração por grupamentos $\mathrm{SH}$, o que resulta na inativação da proteína (CLARKSON, 1997).

O isolado 20 apresenta grande capacidade de resistência e de redução do Cr(VI). Verifica-se que esta atividade foi levemente inibida pela presença da maioria dos íons; porém, a inibição por Mg e Mn foi maior que a observada para o Bacillus sp. ES29. Entre os isolados testados, o 20 foi o que apresentou maior atividade enzimática pela presença de $\mathrm{Cu}$ superando a do controle em quase $80 \%$. O mecanismo pelo qual este íon estimula a ação enzimática ainda não é clara, porém o cobre é um metal de transição, que compõe o grupo prostético de muitas enzimas redutase. São propostas algumas formas de atuação deste metal, como proteção durante o transporte de elétrons, e, em alguns casos, transporte de elétrons entre subunidades da proteína (ABE et al., 2001).

A redução do cromo pelas células eucarióticas ocorre principalmente por ação de redutores não-enzimáticos como o ácido ascórbico.

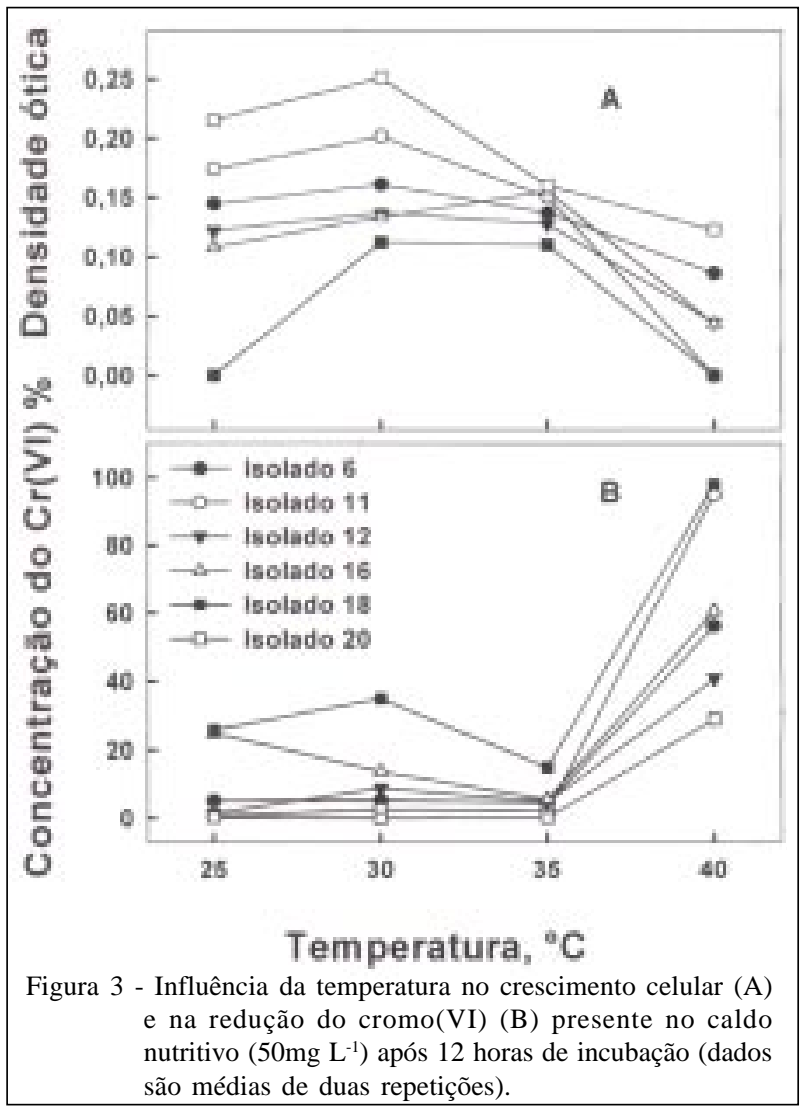

Ciência Rural, v.37, n.6, nov-dez, 2007. 


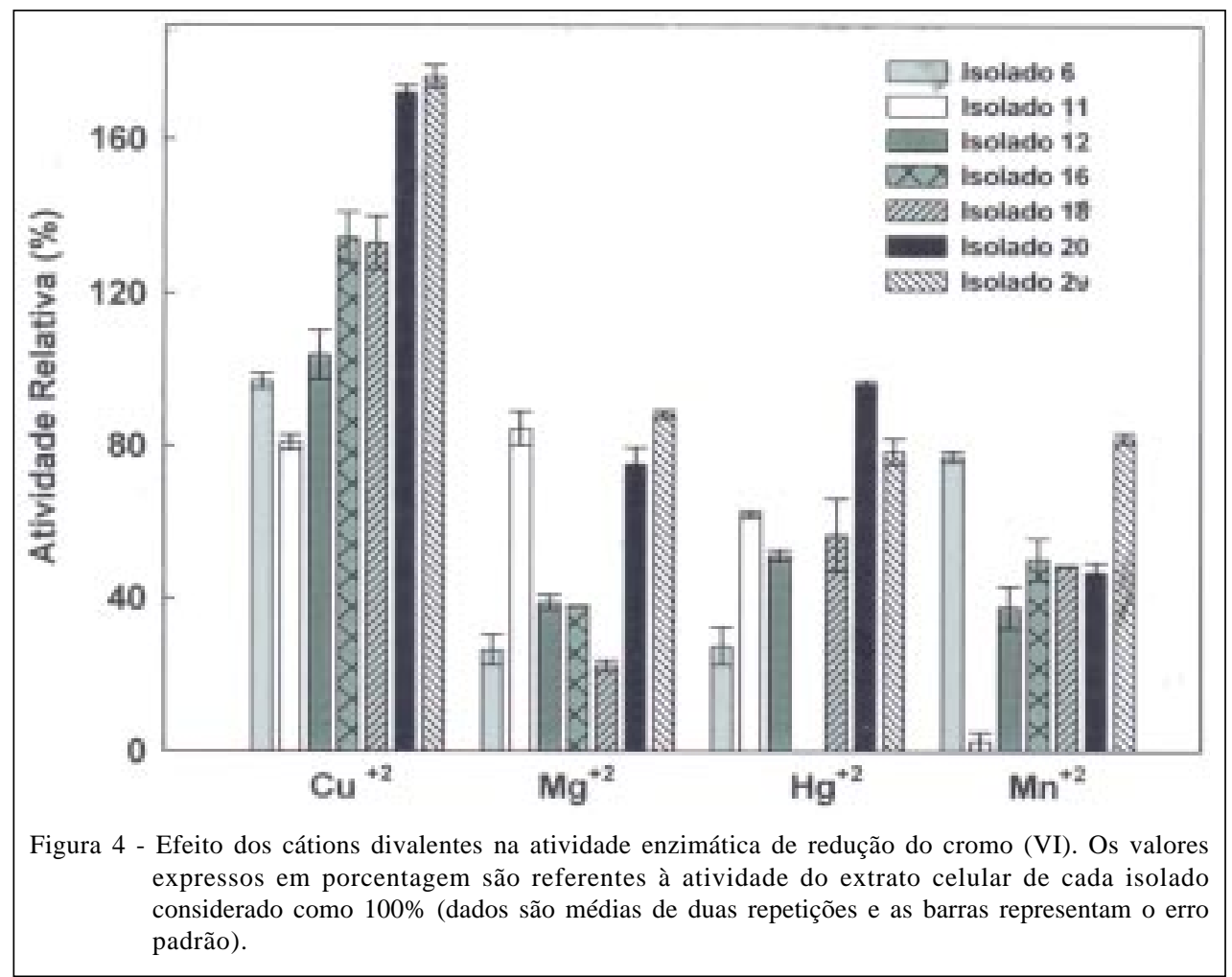

pesados. Não há relato na literatura de bactérias redutoras do cromo(VI) pertencentes ao gênero Xanthobacter, que refere-se ao isolado 12. Dois isolados, 16 e 18, são pertencentes ao gênero Agrobacterium, este gênero é conhecido por apresentar alguns microrganismos patogênicos, causando infecções de raízes. O isolado 20, mais eficiente na redução do $\mathrm{Cr}(\mathrm{VI})$, foi identificado como pertencente ao gênero Bacillus. Muitos microrganismos deste gênero têm sido isolados com atividade de redução do cromo.

\section{CONCLUSÕES}

Entre as 20 bactérias obtidas, as que apresentam maior capacidade na redução do $\operatorname{Cr}(\mathrm{VI})$ foram os isolados $6,11,12,16,18$ e 20 . Todos estes isolados são capazes de crescer em caldo nutritivo com $500 \mathrm{mg} \mathrm{L}-1$ de $\mathrm{Cr}(\mathrm{VI})$, porém apenas os isolados 6, 12 e 20 são resistentes à concentração de $750 \mathrm{mg} \mathrm{L}^{-1}$ de $\mathrm{Cr}(\mathrm{VI})$. Com exceção dos isolados 11 e 18, os demais apresentaram capacidade de redução do $\mathrm{Cr}(\mathrm{VI})$ no caldo nutritivo com pH de 5,0 a 9,0 e temperatura de 25 a $35^{\circ} \mathrm{C}$, demonstrando capacidade de adaptação às variações ambientais. Desta forma, esses organismos apresentam potencial para outros estudos, visando à aplicação em processos de biorremediação.

\section{AGRADECIMENTOS}

Os autores agradecem à Coordenação de Aperfeiçoamento de Pessoal de Nível Superior (CAPES) e ao Conselho Nacional de Desenvolvimento Científico e Tecnológico (CNPQ), pelo apoio financeiro.

\section{REFERÊNCIAS}

AMANN, R. et al. Identification of uncultured bacteria: a challenging task for molecular taxonomists. ASM News, Washington, v.60, p.360-365, 1994.

$\mathrm{ABE}$, F. et al. Isolation of a highly copper-tolerant yeast, Cryptococcus sp., from the Japan Trench and the induction of superoxide desmutase activity by $\mathrm{Cu}^{2+}$. Biotechnology Letters, London, v.25, n.23, p.2027-2034, 2001.

BLINDAUER, C.A. et al. A metallothionein containing a zing flinger within a four-metal cluster protects a bacterium from zinc toxicity. National Academic Society, Washington, v.98, n.17, p.9593-9598, 2001.

BRADFORD, M.M. A rapid and sensitive method for the quantitation of microgram quantities of protein utilizing the principle of protein-dye binding. Analitycal Biochemistry, New York, v.72, n.1-2, p.248-254, 1976.

CAMARGO F.A. et al. Chromate reduction by chromiumresistant bacteria isolated from soils contaminated with dichromate. Journal of Environmental Quality, Madison, v.32, n.4, p.1228-1233, 2003.

Ciência Rural, v.37, n.6, nov-dez, 2007. 
CERVANTES, J.C. et al. Interaction of chromium with microorganisms and plant. FEMS Microbiology Reviews, Amsterdam v.25, n.7, p.335-347, 2001

CODD, R. et al. Studies on the Genotoxicity of Chromium: from the test tube to the cell. Coordination Chemistry Reviews, v.4, n.216, p.537, 2001.

CHIRWA, E.N.; WANG, Y.T. Simultaneous chromium (VI) reduction and phenol degradation in an anaerobic consortium of bacteria. Water Research, Oxford, v.34, n.8, p.2376, 2000 .

CLARKSON, T.W. The toxicology of mercury. Critical Reviews in Clinical and Laboratory Science, Philadelphia, v.34, p.369, 1997.

DERMOU, E. et al. Biological chromium(VI) reduction using a trickling filter. Journal of Hazardous Materials, Amsterdam, v.126, n.1-3, p.78-85, 2005.

DICK, W.A.; TABATABAI, M.A. Significance and potential uses of soil enzimes. In: METTING, F.B. (Eds.). Soil microbial ecology. New York: Marcel Dekker, 1992. p.95-127.

FRANCISCO, R. et al. Diversity of chromium-resistant and reducing bacteria in a chromium-contaminated activated sludge. Journal of Applied Microbiology, Bradford, v.4, n.92, p.837843, 2002.

GRANER, C.A.F. Determinação do crômio pelo método colorimétrico da difenilcarbazida. 1972. 112f. Tese (Doutorado em Ciências) - Universidade Estadual Paulista, Botucatu.
KEYHAN, M. et al. Target of improvement in bacterial chromate bioremediation. Battelle Press, Columbus, v.1, n.6, p.146-150, 2003.

LOUKIDOU, M.X. et al. Equilibrium and kinetic modeling of chromium(V) biosorption by Aeromonas cavie. Colloids and Surfaces A: Physicochemical an Engineering Aspects, Amsterdam, v.242, n.1-3, p.93-104, 2004.

MACFADDIN, J.F. Biochemical test for identification of medical bacteria. Baltimore: Willians and Wilkings, 1980. 928p.

PARK, C.H. et al. Purification to homogeneity and characterization of a novel Pseudomonas putida chromate reductase. Applied and Environmental Microbiology, Washington, v.66, n.5, p.1788-1795, 2000.

STANDEVEN, A.M.; WETTERHAHN, K.E. Ascorbate is the principal reductant of chromium(VI) in rat lung ultrafiltrates and cytosols, and mediates chromium-DNA binding in vitro. Carcinogenesis, Amsterdam, v.13, n.8, p.1319-1324, 1992.

SUZUKI, T. et al. NADPH dependent chromium(VI) reductase of Pseudomonas ambigua G-1: a $\mathrm{Cr}(\mathrm{VI})$ intermediate is formed during the reduction of $\mathrm{Cr}(\mathrm{VI})$ to $\mathrm{Cr}(\mathrm{III})$. Journal of Bacteriology, Baltimore, v.174, n.16, p.5340-5345, 1992.

TEDESCO, M.J. et al. Análises de solo, plantas e outros materiais. 2.ed. Porto Alegre: Departamento de Solos da UFRGS, 1995. 174p. 